\title{
Low-temperature sintering of alkaline niobate based piezoelectric ceramics using sintering aids
}

\author{
Ryo SASAKI, Ryo SUZUKI, Shingo URAKI, ${ }^{*}$ Hirofumi KAKEMOTO and Takaaki TSURUMI ${ }^{\dagger}$ \\ Graduate School of Science and Engineering, Tokyo Institute of Technology, 2-12-1, Ookayama, Meguro-ku, Tokyo $152-8552$ \\ *Konika Minolta IJ Technologies Inc., R\&D Group, Sakura-machi, Hino-shi, Tokyo 191-8511
}

Three kinds of sintering aids, $\mathrm{LiBiO}_{2}, \mathrm{CuBi}_{2} \mathrm{O}_{4}$ and $\mathrm{LiBO}_{2}$, were selected as sintering aids for the low temperature sintering of $\left(\mathrm{Li}_{0.04} \mathrm{~K}_{0.52} \mathrm{Na}_{0.44}\right)\left(\mathrm{Nb}_{0.84} \mathrm{Ta}_{0.1} \mathrm{Sb}_{0.06}\right) \mathrm{O}_{3}$ (LF4) ceramics and the effects of these compounds on the sintering behavior of the LF4 ceramics was investigated. The addition of $\mathrm{LiBiO}_{2}$ decreased the sintering temperature of $\mathrm{LF} 4$ about $100^{\circ} \mathrm{C}$ but the effect was limited and the broadening of XRD peaks due to the degradation of crystallinity was observed. $\mathrm{The}_{\mathrm{CuBi}} \mathrm{O}_{4}$ was also effective to decrease the sintering temperature of $\mathrm{LF} 4$ ceramics but a secondary phase was formed when a large amount of $\mathrm{CuBi}_{2} \mathrm{O}_{4}$ was added. The addition of a small amount of $\mathrm{LiBO}_{2}$ was very effective to decrease the sintering temperature of $\mathrm{LF} 4$ ceramics. By optimizing the sintering conditions, ceramics with the relative density of $95 \%$ were obtained at $950^{\circ} \mathrm{C}$ which was lower than the melting point of $\mathrm{Ag}$. $\mathrm{Li}$ ions in $\mathrm{LiBO}_{2}$ were incorporated into the $\mathrm{LF} 4$ lattices, giving rise to the degradation of piezoelectric properties through the change of crystalline phase. The addition of excess $\mathrm{Na}$ with $\mathrm{LiBO}_{2}$ restricted the incorporation of $\mathrm{Li}$ ions into the lattice. Ceramics sintered at $950^{\circ} \mathrm{C}$ showed the relative permittivity of 738 and the $d_{33}$ constant of $138 \mathrm{pC} / \mathrm{N}$ at room temperature.

(C2008 The Ceramic Society of Japan. All rights reserved.

Key-words : Piezoelectric ceramics, Lead-free materials, Sintering aids, Ceramics processing, Piezoelectricity, Dielectric property

[Received May 19, 2008; Accepted September 11, 2008]

\section{Introduction}

Lead zirconium titanium oxide $\left(\mathrm{Pb}(\mathrm{Zr}, \mathrm{Ti}) \mathrm{O}_{3}, \mathrm{PZT}\right)$ has been widely used in various piezoelectric devices because of its excellent properties controlled by the chemical modifications. ${ }^{1)}$ However, PZT contains huge amount of $\mathrm{Pb}$ that is environmental burdened materials. Although $\mathrm{Pb}$ in electric ceramics is now excluded from the regulation because of the absence of alternative materials to replace PZT-based ceramics, ${ }^{2)}$ lead-free piezoelectric ceramics are desired to be developed and many studied aiming at new lead-free piezoelectric ceramics have been done so far. $^{3)-9)}$

Potassium sodium niobate $\left(\mathrm{K}_{0.5} \mathrm{Na}_{0.5}\right) \mathrm{NbO}_{3}:(\mathrm{KNN})$ is regarded as a candidate material to replace PZT. Saito et al. invented a piezoelectric material represented as $\left(\mathrm{Li}_{0.04} \mathrm{~K}_{0.52} \mathrm{Na}_{0.44}\right)$ $\left(\mathrm{Nb}_{0.84} \mathrm{Ta}_{0.1} \mathrm{Sb}_{0.06}\right) \mathrm{O}_{3}$ (LF4) which showed a high piezoelectric $d_{33}$ constant $(300 \mathrm{pC} / \mathrm{N})$, and could be fired in air. In addition, grain oriented (textured) LF4 ceramics (LF4T) showed $d_{33}=416 \mathrm{pC} / \mathrm{N}$ that was comparable to PZT-based ceramics. ${ }^{3)}$ A problem of $\mathrm{KNN}$-based ceramics including LF4 is a compositional control because $\mathrm{K}$ and $\mathrm{Na}$ easily evaporate in the sintering process. The defects induced by the volatility of $\mathrm{K}$ and Na may decrease the piezoelectric properties. The reduction of sintering temperature should suppress the volatility of these alkaline elements and also improve reproducibility of piezoelectric KNN-based ceramics. Furthermore, a low temperature sintering process will provide a benefit in the application of multilayer piezoelectric actuators where ceramics are sintered with internal metal electrodes. In this case, the sintering temperature is hopefully reduced below the melting point of less expensive $\mathrm{Ag}\left(961^{\circ} \mathrm{C}^{10)}\right)$.

Corresponding author: T. Tsurumi; E-mail: ttsurumi@ceram. titech.ac.jp
In general, the sintering temperature of the ceramics can be reducing by utilizing low-melting point additives as sintering aids. Hayashi et al. reported that lithium bismuth oxide $\left(\mathrm{LiBiO}_{2}\right)$ with a melting point of $700^{\circ} \mathrm{C}$ was effective for the low-temperature sintering of $\left(\mathrm{Pb}_{0.86} \mathrm{Ba}_{0.04} \mathrm{Sr}_{0.12}\right)\left(\mathrm{Zr}_{0.56} \mathrm{Ti}_{0.44} \mathrm{Sb}_{0.02}\right) \mathrm{O}_{3} .{ }^{11)}$ Hasegawa and Otagiri reported that copper bismuth oxide $\left(\mathrm{CuBi}_{2} \mathrm{O}_{4}\right)$ with melting point of $600^{\circ} \mathrm{C}$ was effective for the low-temperature sintering of $\mathrm{BaTiO}_{3}{ }^{12)}$ Lithium metaborate $\left(\mathrm{LiBO}_{2}\right)$, used in the alkali fusion for inorganic analyses, is also expected as a sintering aid though it was not studied so far, because it has a low melting point of $845^{\circ} \mathrm{C}^{13)}$ and previous report revealed that the addition $\mathrm{Li}$ was promoted the sintering of $\mathrm{KNN}$-based ceramics. ${ }^{14)}$

In this study, we investigated the effect of $\mathrm{LiBiO}_{2}, \mathrm{CuBi}_{2} \mathrm{O}_{4}$ and $\mathrm{LiBO}_{2}$-addtions on the sintering behavior of the LF4 ceramics, and measured the dielectric and piezoelectric properties of ceramics finally obtained by the low temperature sintering process proposed in this study.

\section{Experimental procedure}

\subsection{Sample preparation}

The LF4 ceramics were prepared by a conventional solid state reaction process from the raw powders of $\mathrm{K}_{2} \mathrm{CO}_{3}$ (Wako Pure Chemical Ind., Ltd., 99.9\%), $\mathrm{Na}_{2} \mathrm{CO}_{3}$ (Wako Pure Chemical Ind., Ltd., 99.9\%), $\mathrm{Li}_{2} \mathrm{CO}_{3}$ (RARE METALLIC Co., Ltd., 99.99\%), $\mathrm{Nb}_{2} \mathrm{O}_{5}$ (RARE METALLIC Co., Ltd., 99.9\%), $\mathrm{Ta}_{2} \mathrm{O}_{5}$ (Kojundo Chemical Laboratory Co., Ltd., 99.9\%) and $\mathrm{Sb}_{2} \mathrm{O}_{5}$ (Kojundo Chemical Laboratory Co., Ltd., 99.99\%). These powders were mixed to form the chemical composition of $\left(\mathrm{Li}_{0.04} \mathrm{~K}_{0.52} \mathrm{Na}_{0.44}\right)\left(\mathrm{Nb}_{0.84} \mathrm{Ta}_{0.1} \mathrm{Sb}_{0.06}\right) \mathrm{O}_{3}$ by ball milling in dehydration acetone for $24 \mathrm{~h}$. After drying, the mixed powder was calcined at $780^{\circ} \mathrm{C}$ for $4 \mathrm{~h} . \mathrm{LiBiO}_{2}, \mathrm{CuBi}_{2} \mathrm{O}_{4}$ or $\mathrm{LiBO}_{2}$ was added to the $\mathrm{LF} 4$ calcined powder as a sintering aid. $\mathrm{LiBiO}_{2}$ was added to the calcined powder as a mixture of $\mathrm{Li}_{2} \mathrm{CO}_{3}$ and $\mathrm{Bi}_{2} \mathrm{O}_{3}$ powders. 
$\mathrm{CuBi}_{2} \mathrm{O}_{4}$ was first prepared by firing $\mathrm{CuO}$ and $\mathrm{Bi}_{2} \mathrm{O}_{3}$ mixed powders at $720^{\circ} \mathrm{C}$ for $5 \mathrm{~h}$ and added to the $\mathrm{LF} 4$ calcined powder. The particle size of the $\mathrm{CuBi}_{2} \mathrm{O}_{4}$ was 2-5 $\mu \mathrm{m}$. As for $\mathrm{LiBO}_{2}$, a commercial powder (Kojundo Chemical Laboratory Co., Ltd., 99\%) with the particle size of a few $\mu \mathrm{m}$ was added to the calcined powder. After mixing these sintering aids, the LF4 powders were crushed and mixed by ball milling in dehydration acetone for $24 \mathrm{~h}$. After drying, these powders were pressed to pellets using the coldisostatically press (CIP) at $100 \mathrm{MPa}$ and were sintered in air for 1$2 \mathrm{~h}$ at $880-1150^{\circ} \mathrm{C}$ with a temperature rising rate of $2-10^{\circ} \mathrm{C} / \mathrm{min}$.

\subsection{Characterization of ceramics}

The crystalline phases formed in the ceramics were verified by x-ray diffraction (XRD: Rigaku Co., Rint2000) at room temperature. The relative densities of ceramics were evaluated by the Archimedes' method. The microstructure of ceramics was observed by a scanning electron microscopy (SEM: JEOL, JSM5310).

The samples used for dielectric and piezoelectric measurement were cut from ceramic discs. After polishing, Au electrodes were deposited to the sample surfaces by the DC sputtering method. The leakage currents of samples were measured as a function of applied electric $(E)$ field up to $1 \mathrm{kV} / \mathrm{mm}$. Temperature dependences of dielectric permittivity $\left(\varepsilon_{\mathrm{r}}\right)$ and dielectric loss tangent $(\tan \delta)$ of the samples were measured by an impedance analyzer (Agilent, $4294 \mathrm{~A}$ ) at $100 \mathrm{kHz}$ from $25^{\circ} \mathrm{C}$ to $500^{\circ} \mathrm{C}$. The polarization vs. electric hysteresis curves of samples were measured by a ferroelectric tester (Radiant, RT6000). Before the measurements of piezoelectric properties, the samples were poled in sil-

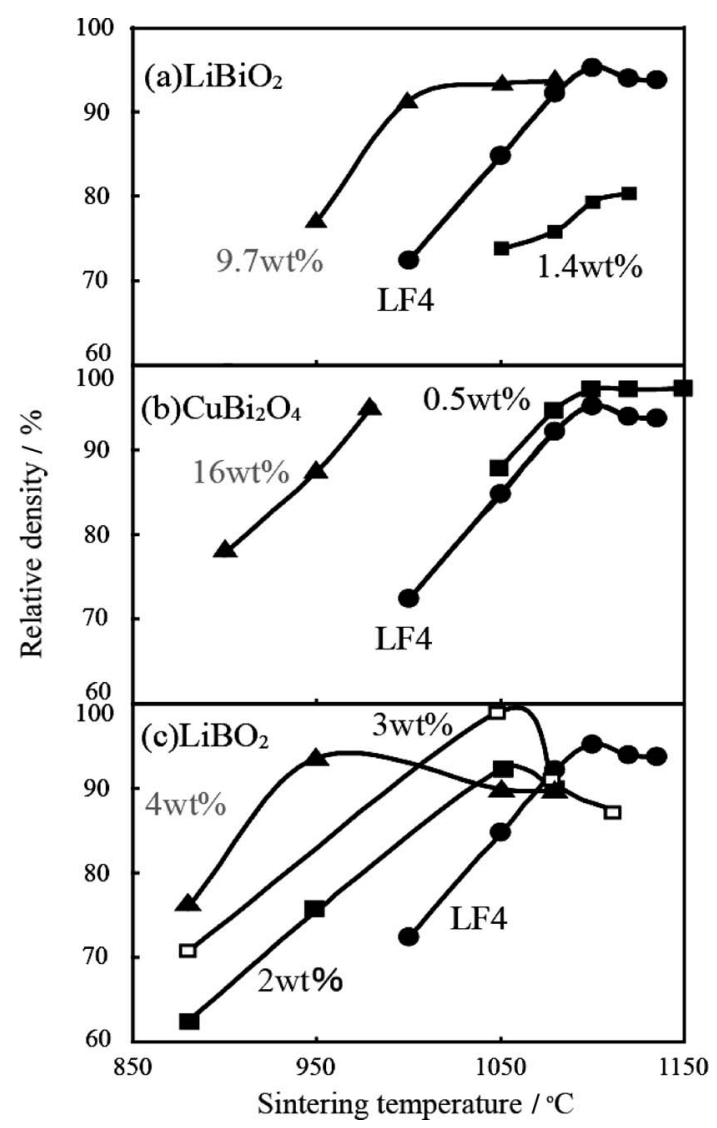

Fig. 1. Relative density of ceramics as a function of sintering temperature. (a) $\mathrm{LiBiO}_{2}$, (b) $\mathrm{CuBi}_{2} \mathrm{O}_{4}$ and (c) $\mathrm{LiBO}_{2}$. icone oil at the electric field of $5 \mathrm{kV} / \mathrm{mm}$ for $20 \mathrm{~min}$ at $100^{\circ} \mathrm{C}$. The piezoelectric properties of samples were measured for 31resonator made of the samples with an impedance analyzer (Agilent, HP4294A) using resonance and anti-resonance method. ${ }^{15)}$ The piezoelectric $d_{33}$ constant was measured with a quasistatic piezoelectric coefficient testing meter (Institute of Acoustics, Chinese Academy of Sciences, ZJ-3B/4B $d_{33}$ Meter).

\section{Results and discussion}

\subsection{Selection of suitable sintering aid}

Figure 1(a) shows the relative densities of $\mathrm{LiBiO}_{2}$-added LF4 ceramics as a function of sintering temperature. The addition of $1.4 \mathrm{wt} \% \mathrm{LiBiO}_{2}$ decreased the sinterability of LF4 ceramics, while the addition of $9.7 \mathrm{wt} \%$ was effective to decrease the sintering temperature about $100^{\circ} \mathrm{C}$ to obtain the same density with the pure LF4 ceramics. The XRD profiles of the LF4 and $\mathrm{LiBiO}_{2}$-added LF4 ceramics are shown in Fig. 2(a) and (b), respectively. Broadening of diffraction peaks observed in the $\mathrm{LiBiO}_{2}$-added LF4 ceramics in comparison with the pure LF4 indicated that the crystallinity of the LF4 degraded with the addition of $\mathrm{LiBiO}_{2}$, which may cause a serious reduction of piezoelectric properties. Furthermore, too much amount of $\mathrm{LiBiO}_{2}$ should be necessary to reach the sintering temperatures below the melting of $\mathrm{Ag}$. From these results, we concluded that $\mathrm{LiBiO}_{2}$ was not suitable as a sintering aid of the LF4 though it worked in the sintering of PZT.

Figure 1(b) shows the relative densities of $\mathrm{CuBi}_{2} \mathrm{O}_{4}$-added LF4 ceramics as a function of sintering temperature. The addition of $0.5 \mathrm{wt} \% \mathrm{CuBi}_{2} \mathrm{O}_{4}$ did not affect the sinterability of LF4, but a notable effect was observed when $16 \mathrm{wt} \% \mathrm{CuBi}_{2} \mathrm{O}_{4}$ was added. A dense ceramics with a relative density over $95 \%$ was obtained by sintering at $980^{\circ} \mathrm{C}$ which was about $170^{\circ} \mathrm{C}$ lower than the case of pure LF4-ceramics. The XRD profiles of $16 \mathrm{wt} \% \mathrm{CuBi}_{2} \mathrm{O}_{4}-$ added LF4 ceramics in Fig. 2(c) indicated that a considerable amount of secondary phase was formed. This result indicated that $\mathrm{CuBi}_{2} \mathrm{O}_{4}$ was not suitable as a sintering aid of the LF4 though it worked in the sintering of $\mathrm{BaTiO}_{3}$.

Figure 1(c) shows the relative densities of the $\mathrm{LiBO}_{2}$-added LF4 ceramics as a function of sintering temperature. The optimum sintering temperature to obtain maximum density of ceramics decreases with increasing amount of $\mathrm{LiBO}_{2}$. The sintering temperature was reduced to $950^{\circ} \mathrm{C}$ when $4 \mathrm{wt} \%$ of $\mathrm{LiBO}_{2}$ was

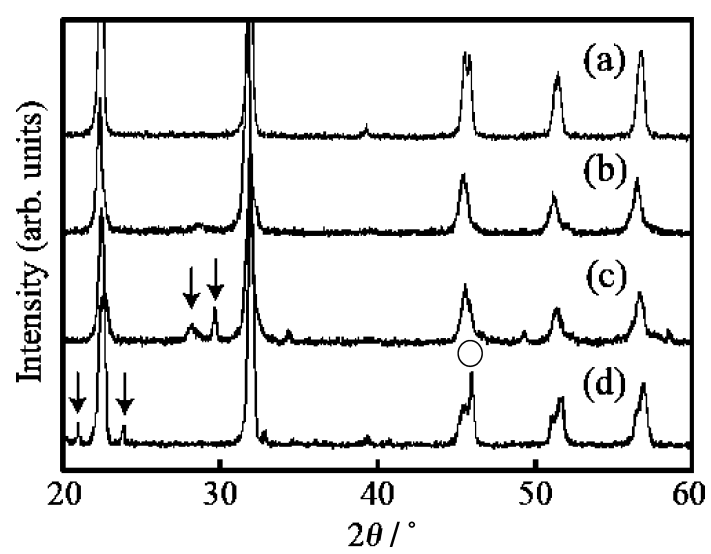

Fig. 2. XRD profiles of ceramics. (a) $\mathrm{LF} 4$ ceramics sintered at $1135^{\circ} \mathrm{C}$, (b) $9.7 \mathrm{wt} \% \mathrm{LiBiO}_{2}$-added $\mathrm{LF} 4$ ceramics sintered at $1000^{\circ} \mathrm{C}$, (c) $16 \mathrm{wt} \%$ $\mathrm{CuBi}_{2} \mathrm{O}_{4}$-added $\mathrm{LF} 4$ ceramics sintered at $980^{\circ} \mathrm{C}$ and (d) $4 \mathrm{wt} \% \mathrm{LiBO}_{2}$ added $\mathrm{LF} 4$ ceramics sintered at $950^{\circ} \mathrm{C}$. 

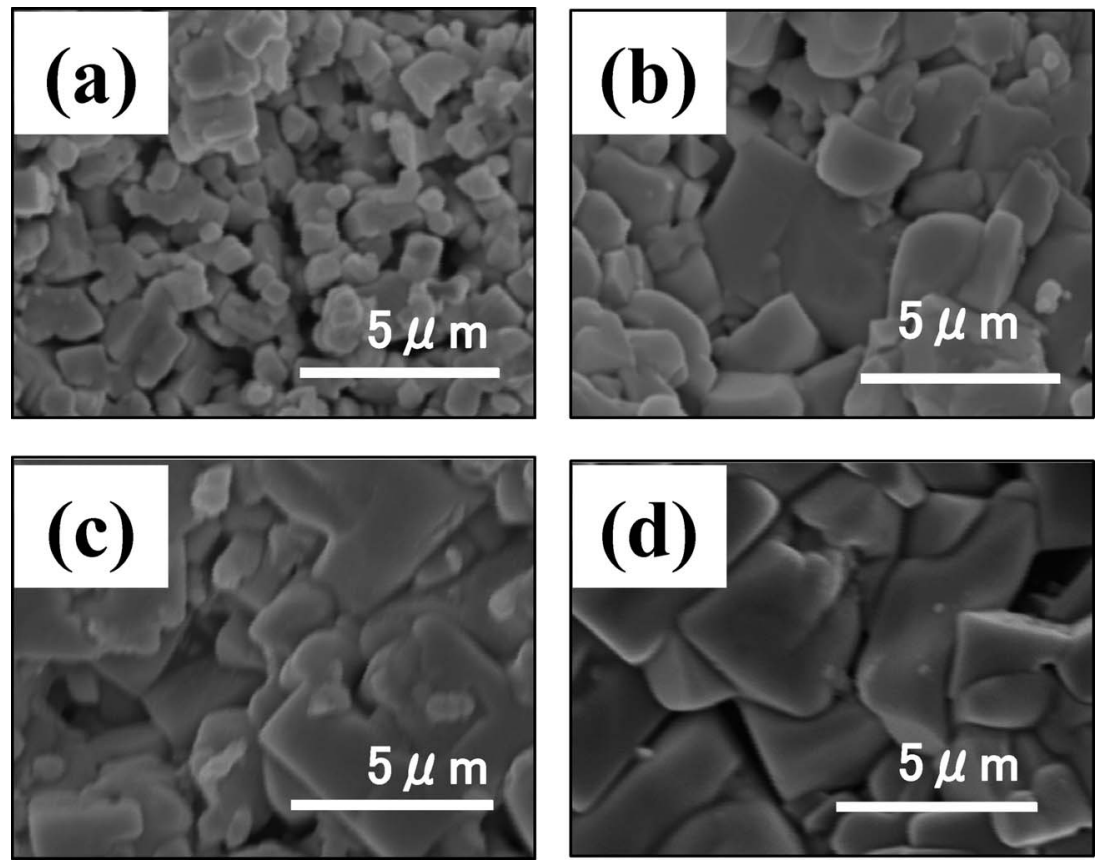

Fig. 3. SEM images of fracture surfaces of LF4 ceramics added with various amount of $\mathrm{LiBO}_{2}$ and sintered at $1050^{\circ} \mathrm{C}$. (a) $0 \mathrm{wt} \%$, (b) $1.5 \mathrm{wt} \%$, (c) $3 \mathrm{wt} \%$ and (d) $4 \mathrm{wt} \%$.

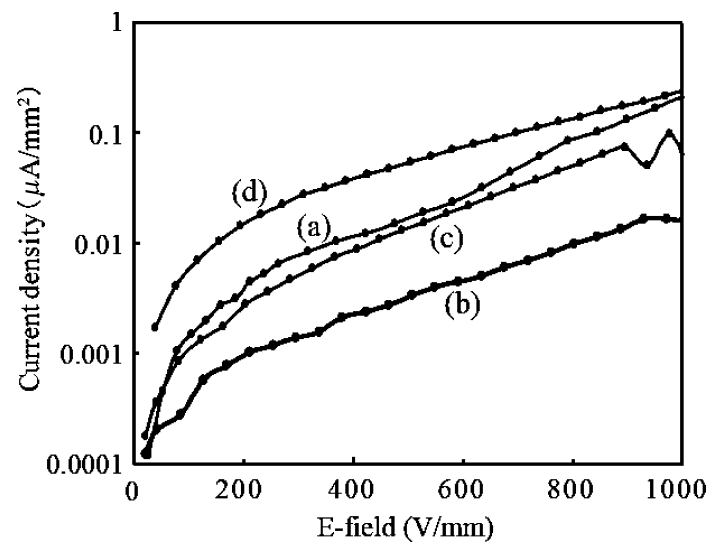

Fig. 4. Current vs. voltage relation of the LF4 ceramics added with different amount of $\mathrm{LiBO}_{2}$. (a) $0 \mathrm{wt} \%$, (b) $1.5 \mathrm{wt} \%$, (c) $3 \mathrm{wt} \%$ and (d) 4 $\mathrm{wt} \%$.

added, which was about $200^{\circ} \mathrm{C}$ lower than that of pure $\mathrm{LF} 4$ ceramics. It was found that the addition of a small amount of $\mathrm{LiBO}_{2}$ was very effective to reduce the sintering temperature of LF4 ceramics. The XRD profile of $4 \mathrm{wt} \% \mathrm{LiBO}_{2}$-added LF4 ceramics is shown in Fig. 2(d). Although two weak peaks of a secondary phase are observed, relatively sharp diffraction peaks of the LF4 phase indicates that the crystallinity of the LF4 phase was hardly degraded by the addition of $\mathrm{LiBO}_{2}$. It should be noted that the shape of diffraction peak marked by a circle in the figure indicated that the crystalline phase changed from orthorhombic (or morphotorpic phase boundary, MPB) to tetragonal, which will be discussed in the later section. Figure 3 shows the SEM images of fracture surfaces of $\mathrm{LiBO}_{2}$-added $\mathrm{LF} 4$ ceramics. The addition of $\mathrm{LiBO}_{2}$ promoted the grain growth of the LF4 ceramics, which was due to the formation of a liquid phase during sintering at temperatures higher than melting point of $\mathrm{LiBO}_{2}\left(845^{\circ} \mathrm{C}\right)$. From these results, we concluded that $\mathrm{LiBO}_{2}$ is the most suitable sintering aid in the three compounds tested in this study.

\subsection{Optimization of chemical composition and sintering process}

The DC current vs. electric field curves $\mathrm{LiBO}_{2}$-added $\mathrm{LF} 4$ ceramics were shown in Fig. 4. The electric insulation of the ceramics increased in the $1.5 \mathrm{wt} \% \mathrm{LiBO}_{2}$-added $\mathrm{LF} 4$ but it decreased when the amount of $\mathrm{LiBO}_{2}$ increased above $3 \mathrm{wt} \%$. The change of electric insulation is attributable to the incorporation of $\mathrm{Li}$ ions into the LF4 lattices. The LF4 ceramics should have $\mathrm{K}$ and $\mathrm{Na}$ vacancies at the A site of perovskite lattices because of the evaporation of these elements during the sintering. By adding $\mathrm{LiBO}_{2}$, the $\mathrm{K}$ and $\mathrm{Na}$ vacancies are filled with the $\mathrm{Li}$ ion in $\mathrm{LiBO}_{2}$ to increase electric insulation. However, the addition of further amount of $\mathrm{Li}$ ions may form other defects in the lattices, giving rise to the decrease of electric insulation as shown in Fig. 4(c) and (d). To obtain high piezoelectric activity, high electric insulation is essentially important to perform the poling process. Therefore, the amount of $\mathrm{LiBO}_{2}$ should be equal or less than $3 \mathrm{wt} \%$, where the electric insulation was in the same range of the pure LF4.

The purpose of this study is to make LF4-based ceramics which can be sintered below the melting point of Ag. To meet this demand, we chose $3 \mathrm{wt} \%$ as a $\mathrm{LiBO}_{2}$ amount and the sintering process of the $3 \mathrm{wt} \% \mathrm{LiBO}_{2}$-added LF4 ceramics was optimized finally as follows: increasing temperature at the rate of $10^{\circ} \mathrm{C} / \mathrm{min}$. to $950^{\circ} \mathrm{C}$ and sintering for $2 \mathrm{~h}$. This process enabled us to make ceramics with a relative density of $95 \%$ without degrading electric insulation. This sample named as LFLB3 was used in the measurements of dielectric and piezoelectric properties mentioned in the next section.

It was mentioned that the crystalline phase in the LF4 changed from the orthorhombic (or MPB) to the tetragonal by adding $\mathrm{LiBO}_{2}$ (Fig. 2(d)). The incorporation of Li ions into the LF4 lattices induced this change. Previous report also pointed out that the increase of $\mathrm{Li}$ content in the LF4 changed the crystalline 
phase to the tetragonal. ${ }^{14)}$ It is known that the piezoelectric activity has a maximum at the MPB. Therefore, the change of crystalline phase may degrade the piezoelectric activity. To avoid this problem, we added $2 \mathrm{~mol} \%$ of excess $\mathrm{Na}$ to the $3 \mathrm{wt} \% \mathrm{LiBO}_{2}$-added $\mathrm{LF} 4$ ceramics. The excess $\mathrm{Na}$ did not change the sinterbility of the ceramics and a relative density over $95 \%$ were obtained at the sintering temperature of $950^{\circ} \mathrm{C}$. This sample was named as LFLB3Na. The XRD profiles around (200) diffraction peak of pure LF4, LFLB3 and LFLB3Na were compared in Fig. 5. It is obvious that the XRD profiles of LF4 and LFLB3Na were almost

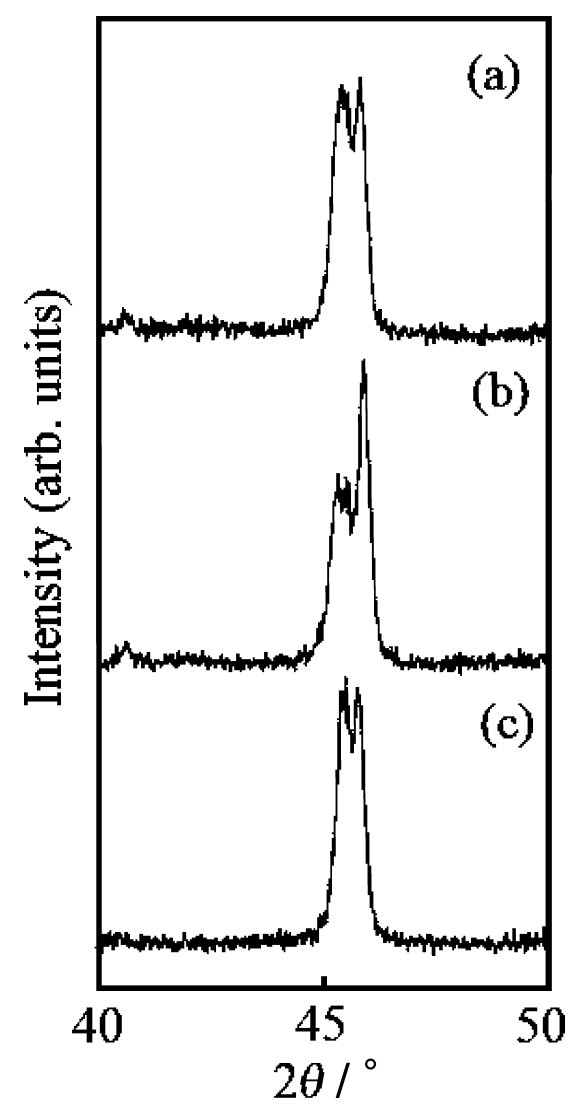

Fig. 5. XRD profiles of (a) LF4, (b) LFLB3 and (c) LFLB3Na ceramics.

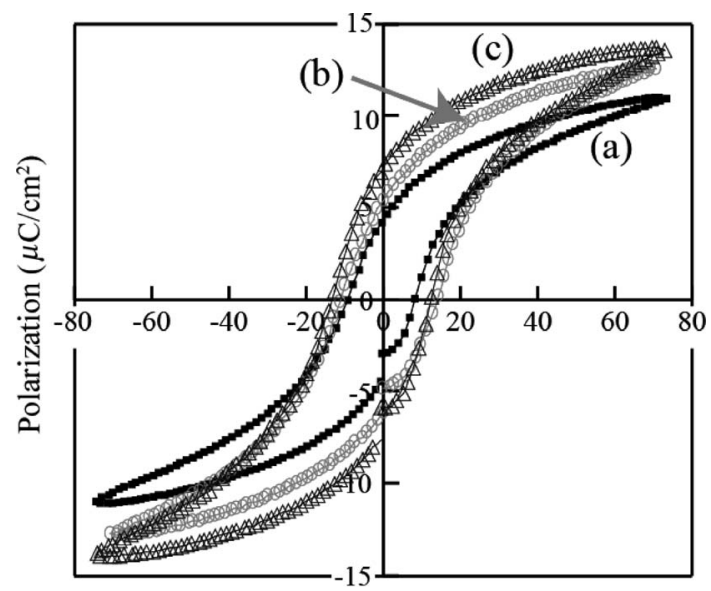

Electric field $(\mathrm{kV} / \mathrm{cm})$

Fig. 6. Polarization vs. electric field hysteresis curves of (a) LF4, (b) LFLB3 and (c) LFLB3Na ceramics. identical, indicating that the tetragonal phase formed in the LFLB3 was changed to the orthorhombic or the MPB by the addition of $2 \mathrm{~mol} \%$ excess $\mathrm{Na}$ which restricted the incorporation of $\mathrm{Li}$ ions in to the LF4 lattices.

\subsection{Dielectric and piezoelectric properties}

Figure 6 shows the $P-E$ hysteresis curves of pure LF4, LFLB3 and LFLB3Na. The remanent polarization $\left(P_{\mathrm{r}}\right)$ of the LF4 was $4.3 \mu \mathrm{C} / \mathrm{cm}^{2}$, it increased to $5.2 \mu \mathrm{C} / \mathrm{cm}^{2}$ in the LFLB3 and to $7.0 \mu \mathrm{C} / \mathrm{cm}^{2}$ in the LFLB3Na. The result indicated that the ferroelectric property of the LF4 did not degrade by the addition of $3 \mathrm{wt} \%$ of $\mathrm{LiBO}_{2}$. Figure 7 shows the temperature dependence of dielectric permittivity $\left(\varepsilon_{\mathrm{r}}\right)$ and loss tangent $(\tan \delta)$ of pure LF4, LFLB3 and LFLB3Na ceramics. The Curie temperature $\left(T_{\mathrm{c}}\right)$ of LFLB3 at $394^{\circ} \mathrm{C}$ is about $80^{\circ} \mathrm{C}$ higher than that of the LF4, which was consistent with the previous report showing that the $\mathrm{Li}$ incorporation into the LF4 lattice increased the Curie temperature. ${ }^{14)}$ The Curie temperature of LFLB3Na decreased in comparison with the LFLB3 because the incorporation of $\mathrm{Li}$ ions into the lattices was restricted by the addition of excess $\mathrm{Na}$. The tan $\delta$ of LFLB3 steeply increased at high temperatures but it was improved in the LFLB3Na. However, the broad maximum of dielectric permittivity in Fig. 6(c) indicated that the addition of $\mathrm{LiBO}_{2}$ sintering aid was not inert to the LF4 lattices even with the presence of excess $\mathrm{Na}$, which cause the degradation of electric properties as mentioned below.

In Table 1 dielectric and piezoelectric properties of the LF4, LFLB3 and LFLB3Na are listed. The addition of $\mathrm{LiBO}_{2}$ to LF4 hardly changed $s^{\mathrm{E}}{ }_{11}$ but decreased $k_{31}, d_{31}, d_{33}$ and $\mathcal{E}_{\text {r }}$. The low dielectric and piezoelectric constants are due to the change of the crystalline phase from the orthorhombic (or MPB) to the tetragonal. The properties of LFLB3 were markedly improved in the

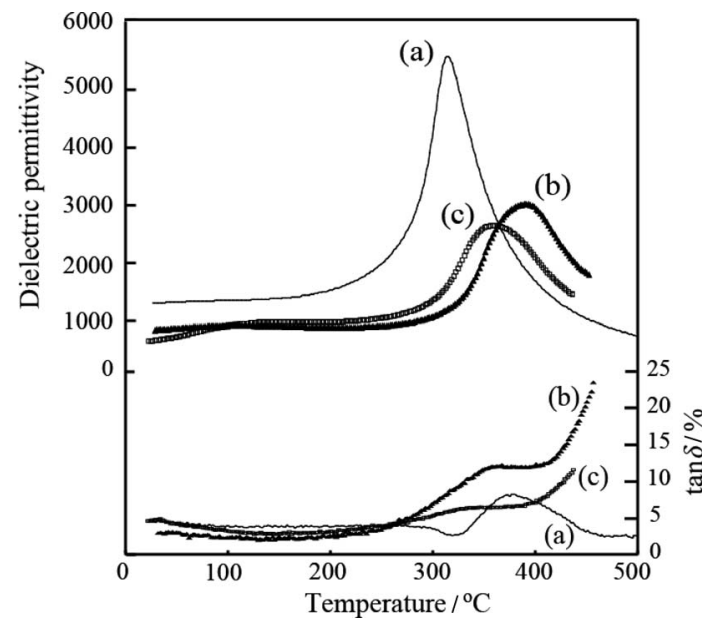

Fig. 7. Temperature dependence of dielectric permittivity of (a) LF4, (b) LFLB3 and (c) LFLB3Na ceramics.

Table 1. Dielectric and Piezoelectric Properties of the LF4, LFLB3 and LFLB3Na Ceramics

\begin{tabular}{ccccrrr}
\hline Sample & $\begin{array}{c}-d_{31} \\
(\mathrm{pC} / \mathrm{N})\end{array}$ & $\begin{array}{c}s^{\mathrm{E}}{ }_{11} \\
\left(\mathrm{pm}^{2} / \mathrm{N}\right)\end{array}$ & $\begin{array}{c}k_{31} \\
(\%)\end{array}$ & $\begin{array}{c}d_{33} \\
(\mathrm{pC} / \mathrm{N})\end{array}$ & $\mathcal{E}_{\mathrm{r}}$ & $\begin{array}{c}T_{\mathrm{c}} \\
\left({ }^{\circ} \mathrm{C}\right)\end{array}$ \\
\hline LF4 & 76 & 10.6 & 21.7 & 225 & 1310 & 316 \\
LFLB3 & 29 & 10.7 & 12.5 & 93 & 580 & 394 \\
LFLB3Na & 44 & 11.5 & 16.3 & 138 & 723 & 362 \\
\hline
\end{tabular}


LFLB3Na and the $d_{33}$ constant of $138 \mathrm{pC} / \mathrm{N}$ was obtained. The chemical modification to approach the MPB is the reason of this improvement, which could be seen in the increase of $s^{\mathrm{E}}{ }_{11}$ indicating the softening of crystal lattices. Although the $d_{33}$ of LFLB3Na ceramics is still much lower than that of the LF4 ceramics, it seems to be acceptable if the low sintering temperature of $950^{\circ} \mathrm{C}$ is taken into account.

In this study, we found that $\mathrm{LiBO}_{2}$ would be an effective sintering aid for the LF4 and possibly for KNN-based piezoelectric ceramics. The $\mathrm{Li}$ ions in $\mathrm{LiBO}_{2}$ were incorporated into the $\mathrm{LF} 4$ lattices to fill up A site vacancies of perovskite structure, which changed the crystalline phase and electric properties. Further studies to optimize both the composition of the $\mathrm{LiBO}_{2}$-based sintering aid and the sintering process should be necessary to minimize the degradation of piezoelectric properties.

\section{Conclusion}

Three candidates of sintering aids, $\mathrm{LiBiO}_{2}, \mathrm{CuBi}_{2} \mathrm{O}_{4}$, and $\mathrm{LiBO}_{2}$, were tested to reduce the sintering temperature of LF4 based ceramics below the melting point of $\mathrm{Ag}$. The addition of $\mathrm{LiBiO}_{2}$ could reduce the sintering temperature but its effect was limited. A secondary phase was formed by the addition of 16 wt $\% \mathrm{CuBi}_{2} \mathrm{O}_{4}$ to decrease the sintering temperature below $1000^{\circ} \mathrm{C}$. In the three candidates, $\mathrm{LiBO}_{2}$ was the most effective to decrease the sintering temperature of LF4 ceramics. By optimizing sintering conditions, the addition of $3 \mathrm{wt} \%$ of $\mathrm{LiBO}_{2}$ enabled us to sinter ceramics with a relative density of $95 \%$ at $950^{\circ} \mathrm{C}$ which was lower the melting point of $\mathrm{Ag}$ However, the incorporation of Li ions into the LF4 lattices changed the crystalline phase to the tetragonal and degraded the piezoelectric properties. The addition of $2 \mathrm{~mol} \% \mathrm{Na}$ with $\mathrm{LiBO}_{2}$ restricted the $\mathrm{Li}$ ion incorporation in the lattice. Ceramics prepared using sintering aids of $\mathrm{LiBO}_{2}$ with the excess $\mathrm{Na}$ showed the relative permittivity of 738 and the $d_{33}$ constant of $138 \mathrm{pC} / \mathrm{N}$ at room temperature.

\section{References}

1) B. Jaffe, W. R. Cook and H. Jaffe, Piezoelectric Ceramics, Academic Press, New York (1971).

2) T. Shiosaki, Ceramics Japan, 40[8], 631-634 (2005)[in Japanese].

3) Y. Saito, H. Takao, T. Tani, T. Nonoyama, K. Takatori, T. Homma, T. Nagaya and M. Nakamura, Nature, 432, 84-87 (2004).

4) M. Matsubara, T. Yamaguchi, K. Kikuta and S. Hirano, Jpn. J. Appl. Phys., 44, 6136-6142 (2005).

5) E. Ringgaard and T. Wurlitzer, J. Eur. Ceram. Soc., 25, 2701-2706 (2005)

6) Y. Hiruma, R. Aoyagi, H. Nagata and T. Takenaka, Jpn. J. Appl. Phys., 44, 5040-5044 (2005).

7) J. Yoo, K. S. Lee, K. Chung, S. Lee, K. Kim, J. Hong, S. Ryu and C. Lhee, Jpn. J. Appl. Phys., 45, 7444-7448 (2006).

8) E. Hollenstein, M. Davis, D. Damjanovic and N. Setter, Appl. Phys. Lett., 87, 182905 (2005).

9) P. Zhao, B. Zhang and J. Li, Appl. Phys. Lett., 90, 242909 (2007).

10) J. Hsu, W. Ko, H. Shen and C. Chen, "IEEE Transactions on Magnetics, Vol.30," Issue. 6 (1994) pp. 4875-4877.

11) T. Hayashi, T. Inoue and Y. Akiyama, Jpn. J. Appl. Phys., 38, 5549-5522 (1999).

12) T. Hasegawa and T. Otagiri, Jpn. J. Appl. Phys., 45, 73607364 (2006).

13) A. Kirfel, G. Will and R. F. Stewart, Acta Cryst., B39, 175185 (1983).

14) Y. Saito and H. Takao, Ferroelectrics, 338, 17-32 (2006).

15) "Standard of Electronic Materials Manufacturers Association of Japan," (EMAS-6100) Nihon Denshi Zairyo Kogyo Kai, Ed. by M. Kadota[in Japanese]. 